\title{
Editorial: Mechanics of masonry gravity structures
}

\section{Matthew Gilbert}

Professor, Department of Civil and Structural Engineering, University of Sheffield, UK

\section{Claudia Casapulla}

Professor, Department of Structure for Engineering and Architecture, University of Naples Federico II, via Forno Vecchio, Napoli, Italy
Masonry gravity structures forming buildings, bridges and other constructions have been built for many centuries, but continue to pose challenges for engineers. Specifically, there is a need to more reliably understand and assess the safety of existing masonry buildings and bridges, and also to conceive more elegant and resource efficient structural solutions for use in new construction, using traditional and emerging new masonry materials. In the case of masonry arch forms, though ubiquitous in buildings and bridges, their mode of interaction with surrounding elements remains poorly understood, and more realistic modelling tools are required to address this.

This two-part themed issue of Engineering and Computational Mechanics focuses on recent developments in analysis and modelling techniques for masonry gravity structures.

In a previous themed issue of the journal (on 'Masonry arches, vaults and domes', published in 2010), plastic limit analysis methods featured prominently (Harvey, 2010; Heyman, 2010; Zessin, et al., 2010; Andreu, et al., 2010; Gilbert, et al., 2010). Due to their power and comparative simplicity such methods remain very popular today, and the first two of the four papers contained in this first part of the themed issue also employ plastic limit analysis methods.

In the first paper, by Pepe et al. (2021), established mathematical programming techniques are used to directly identify the critical failure mechanism and associated load factor for a range of twodimensional masonry arch structures. In addition to modelling hinging failure mechanisms, the formulation allows sliding failures to be modelled and, even though an associative flow rule is adopted, generally conservative predictions of the failure load factor are obtained when the model is applied to the pointed arch models tested experimentally by Misseri et al. (2018).

Although the second paper, by Grillanda et al. (2021), also employs limit analysis, in this case a metaheuristic optimisation algorithm is used to adjust the locations of boundaries between macro-elements describing the failure mechanism. Specifically, the Prey-Predictor Algorithm (PPA) is used and the geometry is conveniently modelled via non-uniform rational Bezier splines (NURBS). Square and skew span masonry arches are modelled, together with a masonry dome structure. It is found that reasonable predictions of the critical failure mechanisms can be obtained, and that for small problems the PPA algorithm is more computationally efficient than traditional genetic algorithms.

The third and fourth papers employ non-linear finite element analysis to model the structures at hand. Although non-linear finite element analysis can be rather computationally intensive, it is capable of modelling a wider range of modes of response than traditional plastic limit analysis methods.

Thus in the third paper Grosman et al. (2021) use non-linear finite element analysis to model the three-dimensional behaviour of masonry arch bridges. Although such structures have traditionally been modelled in two-dimensions, in reality they contain three-dimensional details and are subject to three-dimensional loading regimes. In the paper both detailed (mesoscale) and simplified (macroscale) analysis models are applied to a single span brickwork arch bridge originally tested by Melbourne and Gilbert (1995). It is found that both models are capable of capturing the overall three-dimensional behaviour of the bridge, but that only the detailed (mesoscale) model is capable of representing local damage, such as ring separation.

The final paper, by Di Napoli et al. (2021), is concerned with the analysis of a mixed iron-masonry church, Santa Maria Maddalena, in Ischia, Italy. This is a predominantly masonry structure that incorporates iron and timber elements designed to increase earthquake resistance. Two non-linear static finite element models of the structure are developed, one with and one without the iron and timber elements actually present in the building. The load factors computed when using the unreinforced model are found to be 5-7 times lower than those computed in the model incorporating the iron and timber reinforcement, clearly demonstrating their efficacy.

\section{REFERENCES}

Andreu A, Gil L and Roca P (2010) Analysis of masonry structures by funicular networks. Proceedings of the Institution of Civil Engineers - Engineering and Computational Mechanics 163(3): 147-154, https://doi.org/10.1680/eacm.2010.163.3.147. 
Di Napoli B, Ciocci MP, Celano Tet al. (2021) Seismic behaviour of a mixed iron-masonry church: Santa Maria Maddalena, Ischia. Proceedings of the Institution of Civil Engineers - Engineering and Computational Mechanics 174(2): 114-130, https://doi.org/ 10.1680/jencm.20.00009.

Gilbert M, Smith CC and Pritchard TJ (2010) Masonry arch analysis using discontinuity layout optimisation. Proceedings of the Institution of Civil Engineers - Engineering and Computational Mechanics 163(3): 155-166, https://doi.org/10.1680/eacm.2010.163.3.155.

Grillanda N, Chiozzi A, Milani G and Tralli A (2021) NURBS upper bound prey-predator scheme for collapse analysis of masonry vaults. Proceedings of the Institution of Civil Engineers Engineering and Computational Mechanics 174(2): 82-95, https://doi.org/10.1680/jencm.20.00007.

Grosman S, Bilbao AB, Macorini L and Izzuddin BA (2021) Numerical modelling of three-dimensional masonry arch bridge structures. Proceedings of the Institution of Civil Engineers - Engineering and Computational Mechanics 174(2): 96-113, https://doi.org/ 10.1680/jencm.20.00028.

Harvey W (2010) Briefing: Spreadsheet analysis of complex masonry structures. Proceedings of the Institution of Civil Engineers-
Engineering and Computational Mechanics 163(3): 125-128, https://doi.org/10.1680/eacm.2010.163.3.125.

Heyman J (2010) Equilibrium of masonry arches. Proceedings of the Institution of Civil Engineers - Engineering and

Computational Mechanics 163(3): 129-133, https://doi.org/ 10.1680/eacm.2010.163.3.129.

Melbourne C, Gilbert M (1995) The behaviour of multi-ring brickwork arch bridges. Structural Engineer 73(3): 39-47.

Misseri G, DeJong MJ, Rovero L. (2018) Experimental and numerical investigation of the collapse of pointed masonry arches under quasi-static horizontal loading. Engineering Structures 173: 180-190.

Pepe M, Pingaro M and Trovalusci P (2021) Limit analysis approach for the in-plane collapse of masonry arches. Proceedings of the Institution of Civil Engineers - Engineering and Computational Mechanics 174(2): 66-81, https://doi.org/ 10.1680/jencm.20.00013.

Zessin J, Lau W and Ochsendorf J (2010) Equilibrium of cracked masonry domes. Proceedings of the Institution of Civil Engineers Engineering and Computational Mechanics 163(3): 135-145, https://doi.org/10.1680/eacm.2010.163.3.135. 